\title{
Evaluation of Pigeonpea Accessions and Selected Lines for Reaction to Maruca
}

\author{
K. B. Saxena,* G. D. S. N. Chandrasena, K. Hettiarachchi, Y. B. Iqbal, H. H. D. Fonseka, \\ and S. J. B. A. Jayasekera
}

\begin{abstract}
Maruca vitrata (Geyer) is a serious insect pest of tropical legumes. In Sri Lanka, yield losses due to Maruca damage in pigeonpea [Cajanus cajan (L.) Millsp.] range up to $100 \%$. The development of resistant cultivars and germplasm is one of the best means of control. The objectives of this study were to screen 271 accessions for resistance to $M$. vitrata and evaluate reaction of lines selected from the promising accessions. The high level of natural incidence of Maruca in Sri Lanka provided an opportunity for evaluation of germplasm at Field Crops Research and Development Institute, Maha Illuppallama. Screening of the germplasm accessions revealed large variation in Maruca damage to flowers and pods. On average, the Maruca damage in determinate accessions $(66-75 \%)$ was higher than that of nondeterminate accessions (41-50\%). Resistant plants from four determinate and 12 nondeterminate accessions were selected. Further selection for resistance to Maruca damage among and within lines derived from the resistant plants was exercised for six generations under nonsprayed field conditions. Under insecticide-free conditions, the selections from two accessions showed significant yield advantages over controls. Data on pod damage and larval counts indicated that the resistance was conditioned through yield compensation mechanisms. In pigeonpea, this is the first report of the selection of Maruca resistant lines. Further studies showed that by using the resistant genotypes it is possible to reduce the number of insecticide sprays for economic yields.
\end{abstract}

$\mathrm{P}$ GEONPEA IS AN important rainy season legume crop which is cultivated on about 4.8 million hectares in the dry lands of south Asia, Africa, and Latin America. With good insect control, the traditional photo-sensitive, long-duration cultivars are capable of producing over $3 \mathrm{Mg} \mathrm{ha}^{-1}$ grain yields but, on average, the realized yields are low $\left(0.7 \mathrm{Mg} \mathrm{ha}^{-1}\right)$ and vary considerably across locations and seasons (Saxena, 2000). One of the main reasons for yield instability is due to unpredictable damage caused by a variety of insect pests. In the semiarid tropics Helicoverpa armigera (Hubner) and Melanagromyza obtusa (Malloch) cause serious damage to pigeonpea while under humid tropical environments $M$. vitrata is the major yield reducer (Reed and Lateef, 1990). Maruca vitrata has a number of alternate hosts, which serve as primary sources of infestation. According to Sharma et al. (1999), M. vitrata feeds on 20 genera of six families, the majority of which belong to Papilionaceae.

In pigeonpea, a wide range of maturity is available. The traditional long- (>300 d) and medium- (160-200 d)

K.B. Saxena, International Crops Research Institute for the SemiArid Tropics, Patancheru 502 324, Andhra Pradesh, India; G.D.S.N. Chandrasena, K. Hettiarachchi, Y.B. Iqbal, and H.H.D. Fonseka, Field Crops Research and Development Institute, Maha Illuppallama, (FCRDI), Sri Lanka. S.J.B.A. Jayasekera, Faculty of Agricultural Sciences, Wayamba Univ., Makandura, Gonawilla, Sri Lanka. Received 29 Jan. 2001. *Corresponding author (K.SAXENA@CGIAR. ORG).

Published in Crop Sci. 42:615-618 (2002). duration cultivars are invariably intercropped with cereals such as sorghum [Sorghum bicolor (L.) Moench], pearl millet [Pennisetum glaucum (L.) R.Br.], and maize [Zea mays (L.)]. The short-duration (100-120 d) types, generally grown as a sole crop in crop rotation with wheat (Triticum aestivum L.), are of recent origin, and play a major role in increasing cropping intensity and adoption of pigeonpea across a wider range of latitudes. This development has resulted in the emergence of new cropping systems in the subtropical environments (Saxena, 2000). These types, when sown at the on-set of the rainy season (October-March) in Sri Lanka, commence flowering in the middle or towards the end of the rainy season. The prevalence of high humidity and high temperature during this period provide an ideal environment for oviposition and larval growth of $M$. vitrata, which invariably leads to severe losses of both flowers and young pods.

Losses due to $M$. vitrata have been estimated at $\$ 30$ million annually (ICRISAT, 1992). Patel and Singh (1977) reported 25 to $40 \%$ pod damage due to $M$. vitrata in pigeonpea while 3.7 to $8.9 \%$ yield losses were reported by Patnaik et al. (1986). Sharma et al. (1999) estimated $71 \%$ pod damage in pigeonpea under greenhouse conditions. In Sri Lanka, Dharamasena et al. (1992) reported 84\% yield loss while Joseph and Saxena (1996) observed 90 to $100 \%$ pod damage in the cultivar ICPL 87 under nonsprayed conditions.

The chemical control of $M$. vitrata in pigeonpea in Sri Lanka is difficult because of intermittent rains during the early reproductive phase of the crop. In a susceptible pigeonpea cultivar such as ICPL 87, if the first spray is delayed or rendered ineffective, the subsequent efforts to control Maruca become even more difficult because of webbing and increases in the number and size of larvae. Although some genetic variation for susceptibility to Maruca has been reported in pigeonpea (Prasad et al., 1989; Sahoo and Patnaik, 1993), no systematic efforts have been made to breed resistant cultivars. The first attempt to identify stable sources of resistance to Maruca was made at the Field Crops Research and Development Institute (FCRDI), Maha Illuppallama, Sri Lanka. The objectives of this study were to screen 271 pigeonpea accessions for resistance to $M$. vitrata and to evaluate the lines selected from the promising accessions.

\section{MATERIALS AND METHODS}

An open-field Maruca screening nursery was established in 1990 at FCRDI, in a 0.5-ha block under insecticide-free conditions. The gene bank of International Crops Research

Abbreviations: DAS, days after sowing; DT, determinate type; NDT, nondeterminate type. 
Institute for the Semi-Arid Tropics (ICRISAT) maintains 10315 pigeonpea accessions and from this, 152 determinate (DT) and 119 nondeterminate (NDT) accessions, found promising for yield and adaptation at ICRISAT Center, Patancheru, were identified for this study. These accessions were sown on ridges on 11 October under rainfed conditions along with infestor rows of the highly susceptible cultivar ICPL 87. Each accession was sown in 4-m-long unreplicated single row plots. Interrow spacing was $600 \mathrm{~mm}$ and plants within the row were spaced at $200 \mathrm{~mm}$. The rainfall during the cropping season (October-March) was well distributed, resulting in excellent plant stand and canopy development. The infestor rows of ICPL 87, sown after every three test rows, attracted $M$. vitrata in large numbers resulting in 90 to $100 \%$ pod damage within 75 to $80 \mathrm{~d}$ after sowing (DAS). A nine-point visual assessment scale was used to evaluate the accessions for pod damage 92 DAS, where $1=0 \%$ damage, $2=1$ to $10 \%$ damage, $3=11$ to $25 \%$ damage, $4=26$ to $40 \%$ damage, $5=41$ to $50 \%$ damage, $6=51$ to $65 \%$ damage, $7=66$ to $75 \%$ damage, $8=$ 76 to $90 \%$ damage, and $9=$ greater than $90 \%$ damage.

One hundred eighty-two short-duration accessions were also scored 145 to 155 DAS for their ability to produce a second flush of pods. A five-point visual scale was used for this assessment. The accessions with about 50 pods plant ${ }^{-1}$ or more in the second flush were scored ' 1 ' while those with no pods were scored ' 5 '. Single plants showing least Maruca damage in the first flush of pods with more than 50 healthy pods were selected for progeny row evaluation in the subsequent season. This procedure was repeated for six seasons in the open-field screening nursery during the main rainy season. Each year the selected lines were sown in unreplicated 2 to 4 row plots under nonsprayed conditions along with infestor ICPL 87 after every three rows. Among the germplasm tested, MPG 537-1-3-4 appeared most promising and after three generations of selection, a portion of the seeds harvested from the selected plants were bulked to assess their effectiveness to tolerate Maruca damage. For this experiment, MPG 5371-3-4 was evaluated along with control ICPL 87 with 0,2 , and 3 insecticide sprays during 1994-1995 and 1995-1996 seasons. For two-spray treatment chlorfluazuron [1-[3,5-dichloro-4-(3chloro-5-trifluromethyl-2-pyridyloxy)phenyl]-3-(2,6-diflurobenzyol) urea] $5 \%$ EC at $500 \mathrm{~mL} \mathrm{ha}^{-1}$ was sprayed at $50 \%$ flowering stage and $15 \mathrm{~d}$ later another spray of thiodicarb [dimethyl $N, N^{\prime}$ (thiobis (methylimino) carbonoyloxy)] bisethanimidothioate] $375 \mathrm{~F}$ at $1200 \mathrm{~mL} \mathrm{ha}^{-1}$ was given. The threespray treatment also began with chlorfluazuran 5\% EC at $500 \mathrm{~mL} \mathrm{ha}{ }^{-1}$ spray at $50 \%$ flowering and it was followed by chloropyrifos $[O, O$-diethyl- $O$-(3,5,6-trichloro-2-pyridyl) phosphorothioate] $20 \mathrm{EC}$ at $1500 \mathrm{~mL} \mathrm{ha}^{-1}$, and ethofenprox [2-4(-ethoxyphenyl)-2-methylpropyl 3-phenoxybenzyl ether] (100 $\mathrm{g} \mathrm{L}^{-1}$ ) at $750 \mathrm{~mL} \mathrm{ha}^{-1}$ at $15 \mathrm{~d}$ intervals. The experiments were conducted in a split plot design with four replications under rainfed conditions. The spray treatments were considered as main plots and lines as subplots. Each plot measured 4.8 by $4 \mathrm{~m}$ in size. Larval populations were counted on five random plants in each subplot at 83 DAS. Pod damage (\%) was assessed at maturity from the total pods collected from five random plants in each subplot. The weight $\left(\mathrm{Mg} \mathrm{ha}^{-1}\right)$ of seeds obtained from the interior of each plot $(3.6$ by $3.5 \mathrm{~m})$ was measured to estimate yield.

In 1996-1997 season 14 DT and 14 NDT lines, identified after six generations of selection, were evaluated in separate trials for yield and Maruca damage under rainfed conditions with ICPL 87 as determinate and 'UPAS 120' as nondeterminate controls. The experiments were grown in a split plot design with three replications. Each plot consisted of four rows $4 \mathrm{~m}$ in length. The plants were spaced $200 \mathrm{~mm}$ apart on
$600 \mathrm{~mm}$ wide ridges. The main treatments were sprayed and nonsprayed plots, while the lines were sown in subplots. To enhance insect buildup each subplot was flanked on either side with one row of infestor ICPL 87, sown $10 \mathrm{~d}$ prior to the test entries. In the spray treatment the crop was protected from flowering to pod maturity by applying one spray each of chlorfluazuron, thiodicarb, chloropyrifos, and ethofenprox at 8 to $10 \mathrm{~d}$ intervals. Data on days to flower, days to maturity, and yield were recorded on a plot basis. In all the experiments di-ammonium phosphate at $100 \mathrm{~kg} \mathrm{ha}^{-1}$ was applied as basal dose and the experiments were kept weed free using a preemergence spray of fluchloralin [N-(2-chloroethyl)-2,6-dinitro- $N$-propyl-4-(trifluromethyl) aniline; $N$-(2-chloroethyl)- $\alpha, \alpha, \alpha$ trifluoro-2,6-dinitro- $N$-propyl- $p$-toluidine] at 21 ha $^{-1}$ followed by two or three hand weedings.

\section{RESULTS AND DISCUSSION}

For the accession survey sown in 1990-1991 season, each row of the infestor ICPL 87 scored either 8 or 9 for Maruca damage. The damage score for the 271 accessions evaluated ranged between 3 and 9. A large variation for damage within each growth type was observed. The average damage score of DT accessions was 7.09, and that of NDT accessions was 5.29. Four DT and 12 NDT accessions scored a 3 (10-25\% damage). Eighteen DT accessions recorded total damage (score 9), while none of the NDT accessions was found to be completely damaged.

For the DT accessions days to $50 \%$ flowering ranged between 54 to $84 \mathrm{~d}$ and was not related $(r=0.09)$ to Maruca damage score. Conversely, the NDT accessions flowered between 60 to $105 \mathrm{~d}$ and its relationship with Maruca damage was significant and negative ( $r=$ $-0.43^{* *}$, indicating that early flowering NDT accessions suffered more damage than later flowering accessions. Dharamsena et al. (1992), at the same experiment station, showed that the Maruca population peaks in December-January and declines in the subsequent months. The flowering of early maturing germplasm coincided with peak Maruca activity and resulted in high pod damage. The longer-duration germplasm flowered during the declining phase of Maruca activity resulting in relatively less damage.

Whether short- or long-duration germplasm, the prevailing Maruca population during the test was sufficient to inflict considerable pod losses in the DT types. The clustered inflorescences of the DT pigeonpea plants are more conducive for oviposition, webbing, and larval growth, whereas the long fruiting branches and loose inflorescence of the NDT plants are not preferred by Maruca. Within the short-duration DT group, the recovery from Maruca damage was also poor and out of 152 lines only three scored a 3 , while 34 NDT lines showed appreciable levels of recovery with a score of 3. ICPL 87 did not recover from Maruca damage. This confirmed the observations of Gupta et al. (1991) who also reported higher pod borer damage in the DT types.

The Maruca resistant selection (MPG 537-1-3-4) was evaluated under three insecticide spray regimes. For both years, this resistant selection exhibited superiority over ICPL 87 for each spray treatment (Table 1). Under 
Table 1. Average yield and pod damage of Maruca resistant (MPG 537-1-3-4) and susceptible (ICPL 87) pigeonpea lines under different spray regimes at Maha Illuppallama, during the rainy seasons in 1994-1995 and 1995-1996.

\begin{tabular}{|c|c|c|c|c|c|c|c|}
\hline \multirow[b]{2}{*}{ Season } & \multirow[b]{2}{*}{ No. of sprays } & \multicolumn{3}{|c|}{ Yield } & \multicolumn{3}{|c|}{ Pod damage } \\
\hline & & MPG 537-1-3-4 & $\begin{array}{l}\text { ICPL 87 } \\
\text { (control) }\end{array}$ & Mean & MPG 537-1-3-4 & $\begin{array}{l}\text { ICPL 87 } \\
\text { (control) }\end{array}$ & Mean \\
\hline & & 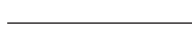 & $\mathrm{ha}^{-1}$ & - & 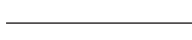 & $\%$ & - \\
\hline \multirow{7}{*}{ 1994-1995 } & 3 & 1.56 & 0.33 & 0.95 & $-\dagger$ & - & - \\
\hline & 2 & 1.30 & 0.37 & 0.84 & - & - & - \\
\hline & 0 & 0.65 & 0.06 & 0.36 & - & - & - \\
\hline & Mean & 1.17 & 0.25 & 0.72 & - & - & - \\
\hline & SEm (sprays) & \pm 0.09 & & & & & \\
\hline & SEm (lines) & \pm 0.13 & & & & & \\
\hline & SEm (lines $\times$ spray) & $\pm \mathbf{0 . 1 1}$ & & & & & \\
\hline \multirow[t]{7}{*}{ 1995-1996 } & 3 & 1.94 & 0.81 & 1.38 & 9.5 & 10.9 & 10.2 \\
\hline & 2 & 1.79 & 0.77 & 1.28 & 11.4 & 10.4 & 10.9 \\
\hline & 0 & 0.81 & 0.28 & 0.55 & 16.3 & 13.5 & 14.9 \\
\hline & Mean & 1.51 & 0.62 & 1.07 & 12.4 & 11.57 & 12.0 \\
\hline & SEm (sprays) & \pm 0.14 & & & $\pm \mathbf{3 . 0 7}$ & & \\
\hline & SEm (lines) & $\pm \mathbf{0 . 1 0}$ & & & $\pm \mathbf{5 . 1 1}$ & & \\
\hline & SEm (lines $\times$ spray) & $\pm \mathbf{0 . 1 2}$ & & & $\pm \mathbf{3 . 9 7}$ & & \\
\hline
\end{tabular}

$\dagger$ Data not recorded.

insecticide-free conditions in the 1994-1995 season, the susceptible control ICPL 87 almost failed to produce seed while MPG 537-1-3-4 produced some yield. Likewise, the yield of MPG 537-1-3-4 was superior to ICPL 87 in 1995-1996. The mean yield superiority of MPG 537-1-3-4 over the control with three spray treatments was $205 \%$ and with two sprays was $171 \%$. Thus, the yield gain from three sprays versus two sprays was negligible.

In the yield trial of lines obtained from further selection for Maruca resistance, variation for days to flower (Table 2) was not significant both under sprayed and nonsprayed conditions. For days to maturity the differences were significant and in general all the lines took a longer time to mature under nonsprayed conditions. For the Maruca resistant selections, maturity was de- layed by 6 to12 $\mathrm{d}$ for DT lines and 8 to $11 \mathrm{~d}$ for NDT lines. For the susceptible controls the delay in maturity in the nonsprayed environment was $31 \mathrm{~d}$ for ICPL 87 and $25 \mathrm{~d}$ for UPAS 120 . Clearly delayed maturity was the result of insect damage and subsequent emergence of second flush flowers.

For sprayed conditions, both DT and NDT selections produced good yields that were comparable to the controls (Table 2). Conversely, for insecticide-free conditions, both DT and NDT selections exhibited distinct superiority in yield over controls, 253 and $203 \%$, respectively. The best DT line, MPG 537-1-3-4-M1-2-1B, recorded $335 \%$ superiority in yield over the control ICPL 87. Among NDT selections, MPG 664-3-6-9-M1-2-M13 had the greatest yield advantage $(213 \%)$ over UPAS

Table 2. Performance of five promising determinate and nondeterminate Maruca resistant pigeonpea selections under sprayed and nonsprayed conditions at Maha Illuppallama, Sri Lanka, in the rainy season 1996-1997.

\begin{tabular}{|c|c|c|c|c|c|c|c|c|c|c|c|}
\hline \multirow[b]{2}{*}{ Lines } & \multicolumn{2}{|c|}{ Days to flowering } & \multicolumn{2}{|c|}{ Days to maturity } & \multicolumn{2}{|c|}{ Seed yield } & \multicolumn{2}{|c|}{ Larval counts } & \multicolumn{2}{|c|}{ Pod damage } & \multirow{2}{*}{$\begin{array}{c}\text { Yield } \\
\text { superiority } \\
\text { over control } \\
\text { under } \\
\text { nonsprayed }\end{array}$} \\
\hline & Sprayed & Nonsprayed & Sprayed & Nonsprayed & Sprayed & Nonsprayed & Sprayed & Nonsprayed & Sprayed & Nonsprayed & \\
\hline & 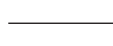 & d & 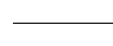 & $-\mathbf{d}-$ & $-\mathbf{m}$ & $\operatorname{g~ha}^{-1}$ & + & no. & 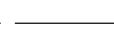 & $\%$ & $\%$ \\
\hline \multicolumn{12}{|l|}{ Determinate (DT) } \\
\hline$\overline{M P G ~ 537-1-3-4-M 1-2-1 B ~}$ & 62 & 62 & 109 & 115 & 2.39 & 2.01 & 6 & & & 19 & 235 \\
\hline MPG 537-1-3-4-M1-2-5B & 59 & 60 & 108 & 120 & 2.07 & 1.83 & 6 & 18 & 4 & 19 & 205 \\
\hline MPG 537-1-3-4-M1-2-M4 & 60 & 62 & 107 & 116 & 2.09 & 1.86 & 8 & 15 & 5 & 18 & 210 \\
\hline MPG 537-1-3-4-M1-2-M13 & 61 & 60 & 107 & 118 & 2.37 & 1.53 & 7 & 16 & 6 & 21 & 155 \\
\hline MPG 537-1-3-4-M1-2-M16 & 58 & 62 & 107 & 115 & 2.09 & 1.62 & 9 & 16 & 5 & 22 & 170 \\
\hline ICPL 87 (control) & 63 & 63 & 119 & 150 & 2.36 & 0.60 & 8 & 16 & 5 & 22 & - \\
\hline Mean of selections & 60 & 61 & 108 & 122 & 2.12 & 1.52 & 7 & 16 & 6 & 20 & _- \\
\hline SEm (lines) & \pm 3.4 & & \pm 4.1 & & $\pm \mathbf{0 . 2 3}$ & & $\pm \mathbf{1 . 0}$ & & \pm 1.4 & & \\
\hline SEm (spray) & $\pm \mathbf{1 . 3}$ & & \pm 2.1 & & \pm 0.08 & & \pm 0.6 & & \pm 1.5 & & \\
\hline SEm (var $\times$ spray) & \pm 2.8 & & \pm 5.3 & & \pm 0.32 & & $\pm \mathbf{1 . 4}$ & & \pm 1.4 & & \\
\hline CV $(\%)$ & \pm 4.1 & & \pm 2.2 & & \pm 21.7 & & $\pm \mathbf{2 1 . 9}$ & & $\pm \mathbf{1 8 . 5}$ & & \\
\hline \multicolumn{12}{|l|}{ Nondeterminate (NDT) } \\
\hline MPG 664-3-6-9-M1-2-M13 & 65 & 63 & 110 & 118 & 2.64 & 2.19 & 4 & 12 & 12 & 18 & 213 \\
\hline MPG 664-3-6-9-M1-2-M2 & 63 & 64 & 109 & 118 & 2.41 & 1.99 & 4 & 12 & 9 & 19 & 184 \\
\hline MPG 664-3-6-9-M1-2-M22 & 69 & 69 & 111 & 122 & 2.25 & 1.67 & 4 & 12 & 10 & 19 & 139 \\
\hline MPG 664-3-6-9-M1-2-M23 & 69 & 71 & 110 & 116 & 2.90 & 1.68 & 2 & 12 & 12 & 21 & 140 \\
\hline MPG 664-3-6-9-M1-2-M27 & 67 & 69 & 110 & 120 & 2.22 & 1.92 & 4 & 9 & 12 & 18 & 174 \\
\hline UPAS 120 (control) & 66 & 66 & 115 & 140 & 2.32 & 0.70 & 3 & 10 & 15 & 20 & - \\
\hline Mean of selections & 66 & 68 & 110 & 120 & 2.50 & 1.42 & 4 & 11 & 11 & 19 & - \\
\hline SEm (lines) & \pm 3.5 & & \pm 3.1 & & \pm 0.20 & & $\pm \mathbf{1 . 4}$ & & \pm 3.1 & & \\
\hline SEm (spray) & $\pm \mathbf{1 . 9}$ & & \pm 2.8 & & \pm 0.08 & & \pm 0.6 & & $\pm \mathbf{1 . 8}$ & & \\
\hline SEm (lines $\times$ spray) & \pm 7.6 & & \pm 5.6 & & \pm 0.29 & & $\pm \mathbf{2 . 0}$ & & \pm 4.4 & & \\
\hline CV $(\%)$ & \pm 3.8 & & $\pm \mathbf{1 . 7}$ & & $\pm \mathbf{1 8 . 0}$ & & $\pm \mathbf{3 2 . 1}$ & & $\pm \mathbf{3 6 . 7}$ & & \\
\hline
\end{tabular}


120. The results of these studies have shown that an open-field screening technique was effective in identifying Maruca resistant genotypes in both DT and NDT growth types. Further evaluation of these genotypes under diverse environments, however, is essential to establish the stability of the resistance.

The larval counts and percentage of pod damage in the selections and controls were similar for nonsprayed conditions (Table 2), indicating that they did not differ for susceptibility to Maruca. However, in comparison with susceptible controls, the Maruca resistant lines recovered quickly from initial floral damage to produce a second flush of flowers. Further, it seems that after this initial damage in the resistant lines, the Maruca larvae were unable to cause significant damage to the new flowers and young pods. Conversely, in the susceptible controls, Maruca continued to cause high flower and pod damage that not only delayed maturity but also reduced yield. In a complementary study conducted in greenhouse conditions, Sharma et al. (1999) demonstrated large differences between the Maruca resistant and susceptible lines for both oviposition and antibiosis. The Maruca resistant lines showed clear nonpreferance for oviposition both under multi and no-choice conditions. They also reported that larvae reared on the Maruca resistant line (MPG 537-1-2-5-M1-2-M5) had significantly lower larval and pupal mass than those reared on the susceptible control ICPL 87 . The fecunditity of the females emerging from the larvae reared on the pods of resistant genotypes was also low (43.4 eggs) compared with that of the susceptible control (100.6 eggs). Thus our results and those of Sharma et al. (1999) suggest that the Maruca resistant reaction in pigeonpea is conditioned by a combination of factors such as oviposition, antibiosis, and tolerance. Tolerance is clearly indicated in this study by the high level of recovery from Maruca damage in the resistant selections because of a yield compensation mechanism conditioned by a second flush of flowers. For a more complete understanding of resistance, additional studies are needed to relate oviposition, larval density, pod damage, recovery, and seed yield.

Pigeonpea has shown great promise in Sri Lanka especially with respect to its adaptation in the rainfed dry lands, paddy-fallows, and degraded soils (Saxena, 1999). Its adoption has been restricted due to severe pest problems, mainly Maruca. The 3 to 5 insecticide sprays that are required for its control account for about $50 \%$ of the pigeonpea production cost in Sri Lanka (Kularatne and Samartunga, 1992). The insecticides not only add to production costs but are an environmental hazard. Considering the severity of Maruca damage of pigeonpea, the performance of the Maruca resistant lines under nonsprayed and limited sprays conditions in this study is encouraging. Recently, Perera and Jinadasa (2000) reported that a Maruca resistant line MPG 537-1-3-4 is performing extremely well in Sri Lanka. Under nonsprayed on-farm trials it has produced 1 to $3 \mathrm{Mg} \mathrm{ha}^{-1}$ yield in comparison to $0.5 \mathrm{Mg} \mathrm{ha}^{-1}$ for ICPL 87. The availability of Maruca resistant pigeonpea lines offers hope for realizing economic grain yields with reasonable production costs. The promotion of such resistant lines for general cultivation may also help in improving yield and stability of pigeonpea in farmers' fields. However, additional on-station and on-farm trials in different agroecological conditions are needed to validate the economic gains of the resistant lines developed in this study.

\section{ACKNOWLEDGMENTS}

The financial support for this research was provided by Asian Development Bank under the Pigeonpea Intercropping and Diversification Study Project in Sri Lanka (TA SRI 1742). The support and encouragement provided by Director and Deputy Director (Research), FCRDI, Maha Illuppallama is acknowledged.

\section{REFERENCES}

Dharamsena, C.M.D., S.M.C. Subasinghe, S.S. Lateef, S. Menike, K.B Saxena, and H.P. Ariyaratne. 1992. Entomology. p. 104-108. In K.B. Saxena et al. (ed.) Pigeonpea varietal adaptation and production studies in Sri Lanka, International Crops Research Institute for the Semi-Arid Tropics (ICRISAT), Patancheru, India.

Gupta, S.C., S.S. Lateef, and R.P. Ariyanayagam. 1991. Are determinates inferior to indeterminate in short-duration pigeonpeas? Intl. Pigeonpea Newsl. 3:11-13.

ICRISAT (International Crops Research Institute for the Semi-Arid Tropics). 1992. The Medium Term Plan. International Crops Research Institute for the Semi-Arid Tropics (ICRISAT), Patancheru, India.

Joseph, K.D.S.M., and K.B. Saxena. 1996. Potential of pigeonpea in sustaining agricultural productivity in Sri Lanka. Paper presented at workshop on multipurpose tree species for food security, Peredeniya, Sri Lanka. 25-27 Oct. 1996. University of Peredeniya, Sri Lanka. (limited distribution).

Kularatne, W.H.D., and P.A. Samartunga. 1992. Economics. p. 110 120. In K.B. Saxena et al. (ed.) Pigeonpea Varietal Adaptation and Production Studies in Sri Lanka, International Crops Research Institute for the Semi-Arid Tropics (ICRISAT), Patancheru, India.

Patel, R.K., and D. Singh. 1977. Serious incidence of pod-borer Maruca testulalis Geyer on red gram at Varanasi. Sci. Culture 43(7):319.

Patnaik, H.P., A.P. Samolo, and B.N. Samolo. 1986. Susceptibility of some early varieties of pigeonpea for pod borers under protected conditions. Legume Res. 9:7-10.

Perera, K.D.A., and D.M. Jinadasa. 2000. p. 70-71. In CLAN collaborative research in Sri Lanka and future plans. International Crops Research Institute for the Semi-Arid Tropics (ICRISAT), Patancheru, India.

Prasad, D., Premchand, and C.M.F. Haque. 1989. Relative susceptibility of different cultivars of red gram. J. Res. Birsa Agric. Univ. $1: 179-181$

Reed, W., and S.S. Lateef. 1990. Pigeonpea pest management. p. 349374. In Y.L. Nene et al. (ed.) The Pigeonpea. CAB Intl., Wallingford, UK.

Sahoo, B.K., and N.C. Patnaik. 1993. Susceptibility of pigeonpea cultivars to pod borers in Orissa. Intl. Pigeonpea Newsl. 18:31-33.

Saxena, K.B. 1999. Pigeonpea in Sri Lanka. International Crops Research Institute for the Semi-Arid Tropics (ICRISAT). Patancheru, India.

Saxena, K.B. 2000. Pigeonpea. p. 82-112. In S.K. Gupta (ed.) Plant breeding: Theory and techniques. Agrobios, Jodhpur, India.

Sharma, H.C., K.B. Saxena, and V.R. Bhagwat. 1999. The legume pod borer, Maruca vitrata: Bionomics and management. Inf. Bull. No. 55. International Crops Research Institute for the Semi-Arid Tropics (ICRISAT). Patancheru, India. 